\title{
Predicting the technical condition of the power transformer using fuzzy logic and dissolved gas analysis method
}

\author{
Vladimir Mikhailovich Levin ${ }^{1}$, Ammar Abdulazeez Yahya ${ }^{1,2}$, Diana A. Boyarova1 \\ ${ }^{1}$ Department of Energy, Novosibirsk State Technical University, Novosibirsk, Russia \\ ${ }^{2}$ Engineering Projects Department, University of Technology, Baghdad, Iraq
}

\begin{tabular}{l} 
Article Info \\
\hline Article history: \\
Received Mar 14, 2021 \\
Revised Oct 28, 2021 \\
Accepted Nov 15, 2021 \\
\hline Keywords: \\
Defect recognition software \\
Dissolved gas analysis \\
Dornenburg ratio method \\
Fuzzy logic \\
Key gas criterion \\
Power transformer \\
Predictive model
\end{tabular}

\begin{abstract}
Power transformers are one of the most important and complex parts of an electric power system. Maintenance is performed for this responsible part based on the technical condition of the transformer using a predictive approach. The technical condition of the power transformer can be diagnosed using a range of different diagnostic methods, for example, analysis of dissolved gases (DGA), partial discharge monitoring, vibration monitoring, and moisture monitoring. In this paper, the authors present a digital model for predicting the technical condition of a power transformer and determining the type of defect and its cause in the event of defect detection. The predictive digital model is developed using the programming environment in LabVIEW and is based on the fuzzy logic approach to the DGA method, interpreted by the key gas method and the Dornenburg ratio method. The developed digital model is verified on a set of $110 \mathrm{kV}$ and $220 \mathrm{kV}$ transformers of one of the sections of the distribution network and thermal power plant in the Russian Federation. The results obtained showed its high efficiency in predicting faults and the possibility of using it as an effective computing tool to facilitate the work of the operating personnel of power enterprises.
\end{abstract}

This is an open access article under the CC BY-SA license.

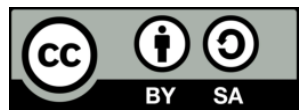

\section{Corresponding Author:}

Ammar Abdulazeez Yahya

Department of Energy, Novosibirsk State Technical University

20 Karl Marx Avenue, Novosibirsk Oblast 630073, Novosibirsk, Russia

Email: ammarazez384@gmail.com

\section{INTRODUCTION}

To ensure the reliability of the power supply system, the electrical equipment forming this system is monitored and diagnosed. power transformers (PT) are among the most important and expensive of this equipment [1]-[5]. There are many methods for diagnosing the technical condition of the PT, for example, dissolved gases (DGA), furan analysis, measurement of the polarization-depolarization current, partial discharge, frequency response analysis, infrared analysis. Many gases are formed as a result of the decomposition of liquid insulators (oil) and solid insulators (paper) as a result of thermal and electrical stresses in the PT [6], [7]. Using the data of these gases dissolved in oil, it is possible to determine the technical condition of the PT and the type of primary defect by the DGA method. There are also various interpretations and standards for the DGA method, such as the duval triangle, the duval pentagon, the IEC ratio, the key gas criterion, the Dornenburg ratio, and the Rogers ratio [8]-[12].

In previous years, many studies have been proposed in which fuzzy logic (FL) was used to diagnose the technical condition of PT. FL is an effective method for determining the technical condition of a transformer, which can work with uncertain and fuzzy information [13]-[17]. FL can combine the practical knowledge of expert diagnosticians with a variety of test data. The FL system is an ideal way to map inputs 
and outputs based on the grammatical rules constructing human understanding rather than on strict mathematical equations.

This paper discusses the use of the DGA method, the key gas criterion, and the Dornenburg ratio method. This complex combination is due to the following factors:

- The DGA method is the most informative among the methods of early detection of defects in oil-filled transformer equipment. It allows diagnosing more than $70 \%$ of faults in the active part of the PT without disconnecting and removing the voltage [18].

- The Key Gas method provides the function of pre-filtering DGA tests for the presence/absence of signs of developing defects. This very important condition ensures the separation of PT in a defect-free state ("norm") from PT in a defective state ("deviation from the norm"). Despite the sufficient conservativeness, the key gas method guarantees a satisfactory level of filtration of defective PT states, subject to additional control of the increase in the key gas release rate [19].

- The Dornenburg ratio method is a fairly stable and reliable tool for recognizing the type of single defects in PT. In the case of superposition of several defects, the Dornenburg ratio method fails, as does the vast majority of known methods for interpreting DGA results [20].

The expected contribution of the authors of the article is the development of a fuzzy predictive model for recognizing defects in power transformers. The extended functionality and sufficient reliability of the FL model are provided by the complex application of well-known methods of interpreting DGA results. Software implementation of the FL model in the LabVIEW environment is considered as a decision support tool for fault-free operation of transformers in power facilities.

\section{THE MAIN THEORETICAL PROVISIONS}

The DGA method is based on measuring the concentrations of seven (or more) major gases: hydrogen, methane, acetylene, ethylene, ethane, carbon monoxide, and carbon dioxide [21]. The developed FL model and its software implementation at the initial stage determine the presence/absence of signs of a developing defect based on the key gas method. The key gas method is based on the amount of defective gases released from the PT insulation structure. The method uses a set of rules to diagnose anomalies such as overheating, corona, and arc discharges.

Detection of a sign of a developing defect in the PT is carried out by comparing the measured values of the concentrations of defective gases with some of the limit values proposed as shown in Table 1, for example, in [22]. These values are in the best agreement with the logical scheme of the Dornenburg ratio method. If the measured values of the concentrations of faulty gases do not exceed the permissible limits, this is a sign of the absence of a defect, i.e., the PT is in a "normal" state. If at least one of the gases has a concentration exceeding the specified limit, this indicates the presence in the RT of a sign of a developing defect and the need to determine the type and degree of danger of the defect.

When a sign of a developing defect is detected in the PT, four ratios of gas concentrations are calculated by the Dornenburg interpretation method. The output data of each gas pair ratio is encoded into a specific code proposed by the authors. For example, if the output of the relationship R1(CH4/H2) is greater than 1 , the code is $\mathrm{A} 1$. If $\mathrm{R} 1$ is less than 0.1 , code is $\mathrm{B} 1$, as shown in Table 2 . The resulting codes represent the input data for the FL model. The codes in Table 2 are used to develop rules of decision making, each of which indicates a specific type of fault, for example, a rule of the form R1=C1, R2=B2, R3=B3, R4=B4 indicates an arc (high-intensity arc discharge), as shown in Table 3.

Table 1. Limit concentrations of dissolved gas

\begin{tabular}{ccccccc}
\hline Key Gases & $\mathrm{H} 2$ & $\mathrm{CH} 4$ & $\mathrm{C} 2 \mathrm{H} 6$ & $\mathrm{C} 2 \mathrm{H} 4$ & $\mathrm{C} 2 \mathrm{H} 2$ & $\mathrm{CO}$ \\
\hline Concentrations limits (ppm) & 100 & 120 & 65 & 50 & 1 & 350 \\
\hline
\end{tabular}

Table 2. Dornenburg ratio codes

\begin{tabular}{clcc}
\hline Ratio 1 (R1) & Ratio 2 (R2) & Ratio 3 (R3) & Ratio 4 (R4) \\
CH4/H2 & $\mathrm{C} 2 \mathrm{H} 2 / \mathrm{C} 2 \mathrm{H} 4$ & $\mathrm{C} 2 \mathrm{H} 2 / \mathrm{CH} 4$ & $\mathrm{C} 2 \mathrm{H} 6 / \mathrm{C} 2 \mathrm{H} 2$ \\
\hline $\mathrm{R} 1>1=\mathrm{A} 1$ & $\mathrm{R} 2<0.75=\mathrm{A} 2$ & $\mathrm{R} 3<0.3=\mathrm{A} 3$ & $\mathrm{R} 4>0.4=\mathrm{A} 4$ \\
$\mathrm{R} 1<0.1=\mathrm{B} 1$ & $\mathrm{R} 2>0.75=\mathrm{B} 2$ & $\mathrm{R} 3>0.3=\mathrm{B} 3$ & $\mathrm{R} 4<0.4=\mathrm{B} 4$ \\
$0,1<\mathrm{R} 1<1=\mathrm{C} 1$ & & & \\
\hline
\end{tabular}

The formation of the FL model involves three sequential processes: fuzzification, fuzzy inference, and defuzzification [23]-[28]. The fuzzification process aims to convert the gas ratios into fuzzy input 
memberships. The curve that determines the correlation of the input value with the degree of membership is called the membership function (MF). The curve can have various shapes, such as triangular, Gaussian, Sigmoidal, and others. The values of this function belong to the range from 0 to 1 . MF is described using (1). Figure 1 shows a graphical interpretation of the trapezoidal MF and its generalized parameters that characterize the fuzzy interval of changes in the input variables. The input membership for a fuzzy model using developed codes of the four Dornenburg ratios: R1, R2, R3, R4 is shown in Figure 2.

$$
M F=\max \left\{\min \left(\frac{x-a}{c_{1}-a}, 1, \frac{b-x}{b-c_{2}}\right), 0\right\}
$$

Table 3. Fault classification based on codes

\begin{tabular}{cccccc}
\hline N & R1 & R2 & R3 & R4 & Suggested fault diagnosis \\
\hline 1 & B1 & - & A3 & A4 & Partial discharge (low-intensity PD) \\
2 & C1 & B2 & B3 & B4 & Arcing (high-intensity PD) \\
3 & A1 & A2 & A3 & A4 & Thermal decomposition \\
\hline
\end{tabular}

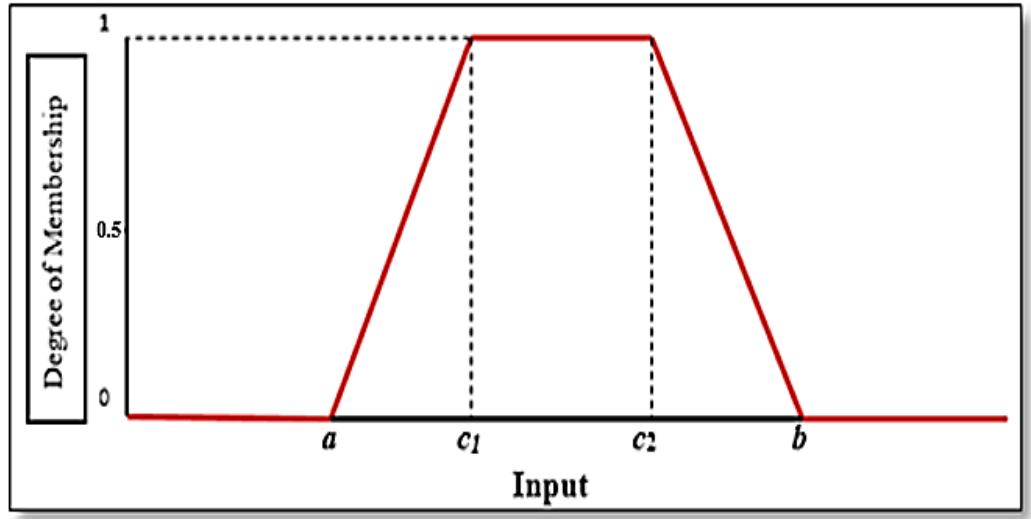

Figure 1. Generalized representation of the trapezoidal MF

The minimum and maximum limits of the MF of the input variable $\mathrm{x}$ are $\mathrm{a}$ and $\mathrm{b}$. The coordinates $\mathrm{c}_{1}$ and $c_{2}$ are the centers of the MF. The MF reaches the maximum degree of membership (DOM) whenever the input variable is located between $c_{1}$ and $c_{2}$. If the value of the input variable is located between a and $c_{1}$, as well as between $b$ and $c 2$, then the DOMs values can be in the range from 0 to 1 . The software implementation of the FL model using the LabVIEW package provides built-in scaling of the ranges of input and output variables. Figure 2 shown, as an example, the scaling of the R2 ratio range for the previously described codes A2 and B2. The used fuzzy inference system (FIS) is responsible for selecting inferences from a knowledge-based set of linguistic variables of the "if-then" type of fuzzy rules. In the system of FL proposed by the authors, 12 rules were formulated, as shown in Figure 3.

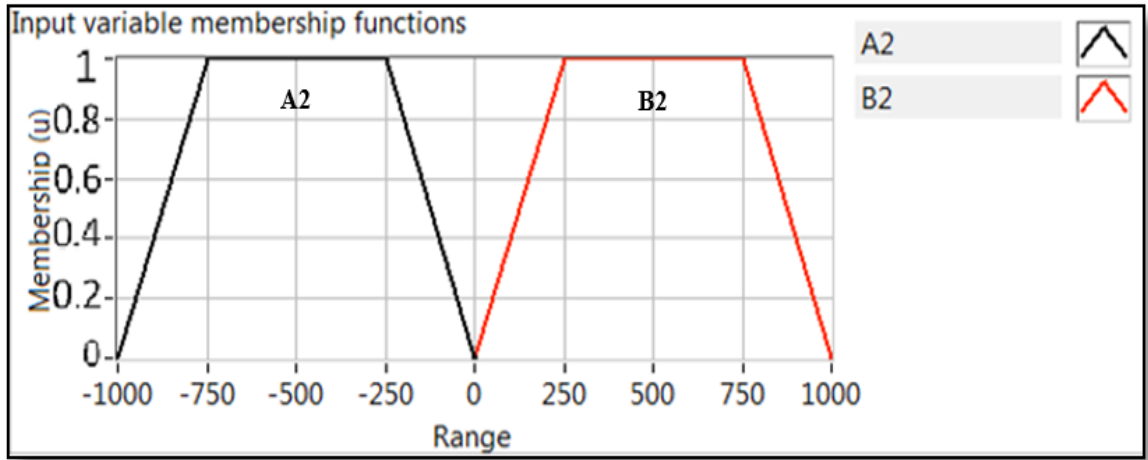

Figure 2. Scaling the range of the input variable R2 to describe the membership functions for codes A2, B2 


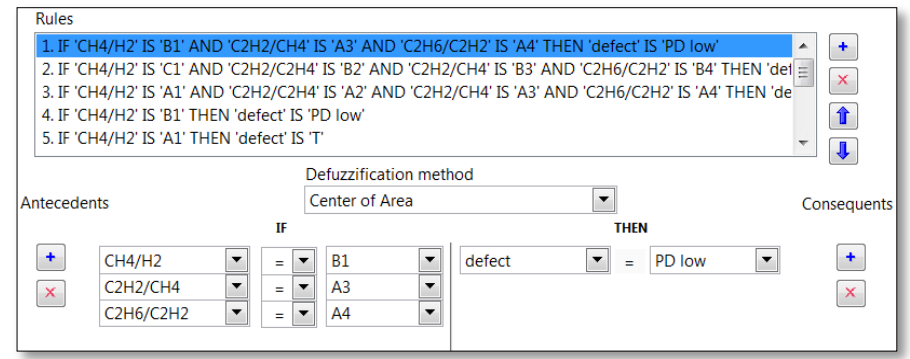

Figure 3. Fuzzy rules for the proposed FL model

The defuzzification then converts the fuzzy output values back into clear output actions, the fuzzy value obtained from the MF of the truncated output signal is calculated at the defuzzification stage of the FL system using the Mamdani formula (2). Figure 4 shows the ranges of variation of the fuzzy output variable of the FL model for the three codes that characterize the types of faults in the transformer, which are indicated in Table 3, by the Dornenburg interpretation.

$$
Z_{0}=\frac{\int z, \mu(z) d z}{\int \mu(z) d z}
$$

Here, $\mathrm{z}$ the fuzzy output variable, $\mathrm{Z}_{0}$ the centroid of the truncated output of the MF, $\mu(\mathrm{z})$ the degree of membership of the truncated MF.

The result of fuzzy inference can be obtained using the Mamdani Max-Min composition technique. Here the logical "AND" is replaced by the minimization operator, and the logical "OR" is replaced by the maximization operator. The developed set of fuzzy rules connects the input and output variables for the Dornenburg ratio method and shown in 3D surface plots as shown in Figure 5.

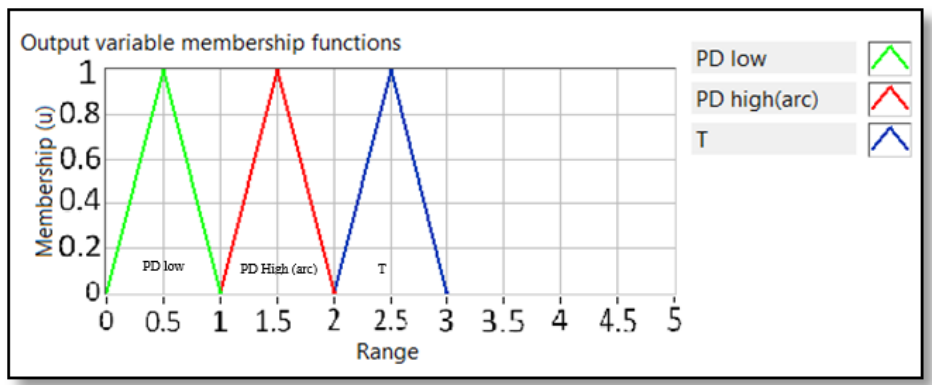

Figure 4. The ranges of variation of the fuzzy output variable for different types of faults

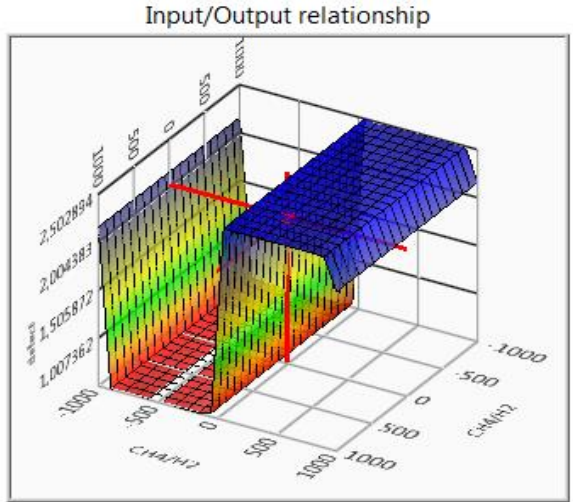

Figure 5. 3D surface plots for Dornenburg ratio method 
A simulation program was created using LabVIEW 2018 to apply and test the proposed approach to FL, the Dornenburg method. Figure 6 shows the program interface. The interface of the program consists of units for entering the values of the five main gases $(\mathrm{H} 2, \mathrm{CH} 4, \mathrm{C} 2 \mathrm{H} 2, \mathrm{C} 2 \mathrm{H} 4$, and $\mathrm{C} 2 \mathrm{H} 6)$ and four lampsindicators in different colors. Each lamp represents a specific condition such as normal, thermal defect, arc defect and partial discharge. A dialogue box that gives the code of defect, and a dialogue box that gives a message of the type of defect also take place. Figure 7 shows the algorithm of the program.

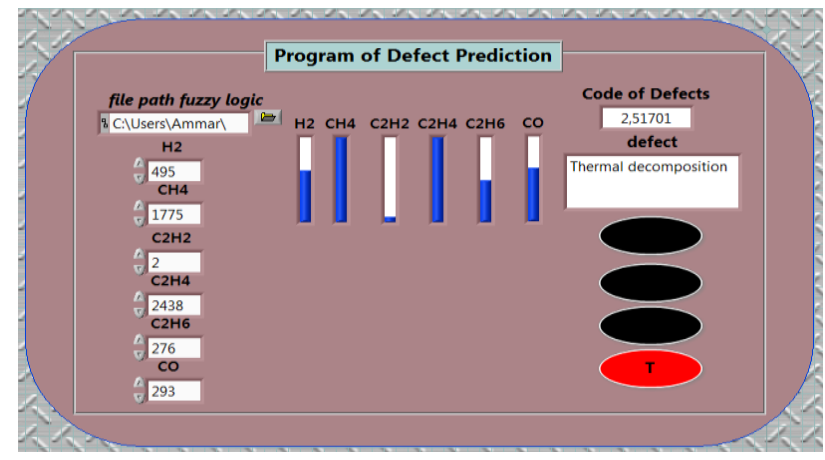

Figure 6. Front panel for the program interface

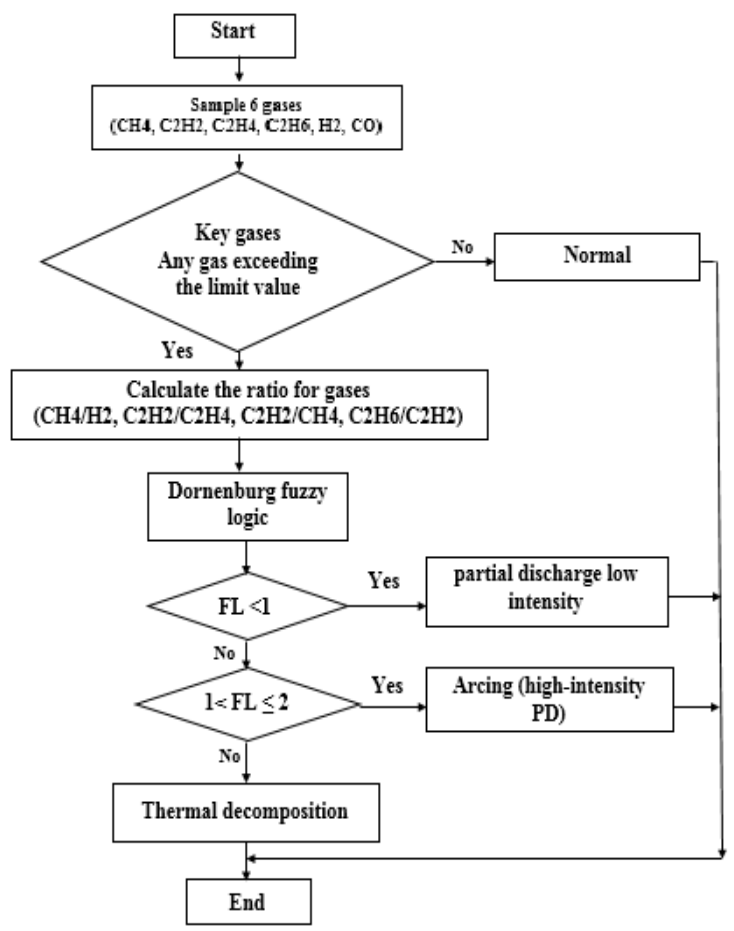

Figure 7. The algorithm of the program

\section{CALCULATION RESULTS ANALYSIS AND DISCUSSION}

The developed fuzzy model and its software implementation were tested on a transformer of the type TDN-250000/220 kV of one of the thermal power stations (TPS) of Russia. At the same time, testing was carried out on a retrospective of 146 DGA protocols for the twenty years of the transformer operation. The results obtained showed that $39 \%$ of the samples indicated a normal state (defects-free) and $61 \%$ of the samples indicate a deviation from normal. $89 \%$ of the deviation samples indicate a thermal defect, and $11 \%$ indicate an electrical defect. Table 4 shows some of the results obtained from the model and program test. As a sample for comparing ratings when checking the developed model and program, the operating conclusions based on the diagnostic test reports and the acts of opening the transformer during repairs are accepted. For each of the 146 DGA tests (gas concentrations are given in ppm), the developed FL model and its software 
implementation demonstrated maximum agreement with the operational conclusions used. The results obtained allow us to count on the fact that the developed program meets the requirements for reliable detection of defects in power transformers and will significantly simplify the work of the power plant maintenance personnel.

For more convincing confirmation of the reliability of the FL model developed by the authors and the program for assessing the state of transformers according to the DGA data, the article compares it with the results of a well-known study [29]. The results of the comparison showed a $90 \%$ coincidence of the results of the developed program with the results given in the study [29]. The difference between the results in samples 6 and 7 is shown in Table 5 in red. Sample 6 in [29] indicates a thermal defect, and the program result indicates no deviations ("normal"). Gas concentrations in sample 6 as shown in Table 5 are very small and do not exceed the permissible limit values as shown in Table 1. This indicates that there is no reason to recognize the condition of the transformer as faulty, which is consistent with the result of the evaluation according to the developed program.

Table 4. DGA protocols of the transformer TDN-250000/220 kV of the TPS (fragment)

\begin{tabular}{ccccccccc}
\hline Data & H2 & CH4 & C2H4 & C2H6 & C2H2 & CO & Operating Conclusions & Program Verification \\
\hline 26.10 .1994 & 47.2 & 27.4 & 28.5 & 0.1 & 0.1 & 150 & Normal & Normal \\
17.05 .1995 & 4.24 & 1.5 & 2.18 & 0.57 & 0.03 & 130 & Normal & Normal \\
04.06 .1998 & 1 & 3.76 & 18 & 12.9 & 0.5 & 45 & Normal & Normal \\
18.11 .2003 & 2.1 & 83.5 & 49.9 & 51.3 & 0.7 & 210 & Normal & Normal \\
21.06 .2006 & 111 & 100.1 & 100.6 & 37.9 & 10.6 & 290 & Thermal & Thermal \\
30.06 .2006 & 18 & 100.1 & 111.6 & 43.1 & 11.9 & 290 & Thermal & Thermal \\
14.07 .2006 & 19.1 & 72.7 & 91.5 & 33.2 & 24.7 & 170 & Thermal & Thermal \\
26.02 .2007 & 12.9 & 329 & 49.9 & 20.7 & 15.1 & 100 & Thermal & Thermal \\
10.07 .2007 & 31.9 & 25.9 & 157 & 25.6 & 12.1 & 240 & Arcing & Arcing \\
13.09 .2007 & 68.2 & 211.7 & 229.4 & 86.7 & 40.9 & 200 & Thermal & Thermal \\
13.02 .2008 & 71.4 & 178.3 & 461.6 & 93.9 & 21 & 30 & Thermal & Thermal \\
04.03 .2008 & 117.7 & 278.8 & 527.8 & 136.8 & 28.1 & 170 & Thermal & Thermal \\
10.04 .2008 & 105.5 & 313.9 & 619.9 & 119.2 & 23.1 & 150 & Thermal & Thermal \\
28.12 .2009 & 88.5 & 263.5 & 531.2 & 61.2 & 8.9 & 380 & Thermal & Thermal \\
22.06 .2010 & 15.3 & 231.9 & 466.8 & 58.9 & 3.1 & 360 & Thermal & Thermal \\
02.12 .2010 & 8.1 & 131.5 & 289.9 & 52.6 & 1 & 260 & Thermal & Thermal \\
05.06 .2011 & 15.9 & 147.9 & 257.1 & 34 & 1.4 & 370 & Thermal & Thermal \\
26.09 .2011 & 4 & 169.9 & 316.6 & 66.8 & 0.8 & 400 & Thermal & Thermal \\
26.04 .2012 & 26.7 & 230.1 & 562.6 & 163 & 12.7 & 460 & Thermal & Thermal \\
14.08 .2012 & 14.5 & 734 & 1398.7 & 227.6 & 5.8 & 1860 & Thermal & Thermal \\
\hline
\end{tabular}

Table 5. DGA data (ppm) and comparison of the results of the study [29] and this study

\begin{tabular}{ccccccccc}
\hline $\mathrm{N}$ & $\mathrm{H} 2$ & $\mathrm{CH} 4$ & $\mathrm{C} 2 \mathrm{H} 2$ & $\mathrm{C} 2 \mathrm{H} 4$ & $\mathrm{C} 2 \mathrm{H} 6$ & $\mathrm{CO}$ & Model [29] & Program Verification \\
\hline 1 & 495 & 1775 & 2 & 2438 & 276 & 293 & Thermal & Thermal \\
2 & 80 & 619 & 1 & 2480 & 326 & 268 & Thermal & Thermal \\
3 & 21 & 24 & 1 & 98 & 23 & 159 & Thermal & Thermal \\
4 & 231 & 3997 & 1 & 5584 & 1726 & 0 & Thermal & Thermal \\
5 & 127 & 24 & 81 & 32 & 1 & 0 & Arcing & Arcing \\
6 & 2 & 7 & 1 & 1 & 1 & 0 & & \\
7 & 217 & 286 & 884 & 458 & 14 & 176 & & Normal \\
8 & 54 & 1 & 1 & 4 & 1 & 106 & Normal & Arcing \\
9 & 246 & 43 & 53 & 21 & 1 & 218 & Arcing & Arcing \\
10 & 9474 & 4066 & 12.997 & 6552 & 353 & 553 & Arcing & Thermal \\
11 & 507 & 1053 & 17 & 1440 & 297 & 22 & Thermal & Thermal \\
12 & 416 & 695 & 1 & 867 & 74 & 200 & Thermal & Normal \\
13 & 47 & 12 & 1 & 8 & 1 & 115 & Normal & Arcing \\
14 & 441 & 207 & 261 & 224 & 43 & 161 & Arcing & Thermal \\
15 & 18.9 & 46.9 & 1 & 61.54 & 6.9 & 371 & Thermal & Thermal \\
16 & 116.6 & 623 & 2.87 & 1683.5 & 416 & 317 & Thermal & Thermal \\
17 & 200 & 700 & 1 & 740 & 250 & $\mathrm{~N}$ & Thermal & Arcing \\
18 & 300 & 490 & 95 & 360 & 180 & $\mathrm{~N}$ & Arcing & Thermal \\
19 & 56 & 61 & 31 & 32 & 75 & $\mathrm{~N}$ & Thermal & Normal \\
20 & 33 & 26 & 0.2 & 5.3 & 6 & $\mathrm{~N}$ & Normal & \\
\hline
\end{tabular}

As for result 7, it indicates a thermal defect in the study [29]. The evaluation of the state of the PT according to the program indicates an electrical defect (arc). The excess of the concentration of acetylene $(\mathrm{C} 2 \mathrm{H} 2)$ of its limit norm indicates an electrical defect (arc), which meets the requirements of [22] and is in agreement with the result of the proposed program. Thus, the results of testing the FL model and the software for recognizing defects in the PT give reason to expect that with successful additional tests on independent 
and verified data, they will be able to take a prominent position as a decision support tool for the defect-free operation of equipment.

\section{CONCLUSION}

Methods of monitoring and diagnosing power transformers are designed to ensure their working condition and reliable operation of electrical installations. The DGA method is the most informative method for early detection of developing defects in oil-filled transformer equipment. It allows detecting defects at an early stage of development before they pass into a critical phase and lead to catastrophic consequences. A software implementation of the FL model for assessing the technical condition of power transformers as an expert system for predicting faults is proposed. The fuzzy predictive model based on the application of the Key Gas and Dornenburg ratio methods to interpret the results of the analysis of gases dissolved in oil. The use of the key gas criterion at the initial stage of assessing the condition of the transformer allows you to identify signs of the presence or absence of a developing defect in it. Then, in the case of a detected deviation from the norm, the Dornenburg ratio method and fuzzy logic used to predict the type of defects in the transformer. Verification of the developed FL model was carried out on 146 tests of the DGA of a $220 \mathrm{kV}$ transformer of a thermal power station in Russia. The results of the assessments obtained with the help of the program are as consistent as possible with the operational conclusions of specialists in the operation and test reports. This indicates the high accuracy of the program for interpreting the results of the DGA of transformers when evaluating and predicting their technical condition. In addition, to confirm the reliability of the program, gas data were taken from a case study and compared with the results of a well-known publication. Between the results of the published study and the study of the authors of the article, a large overlap was found, up to $90 \%$. The comparison of the revealed differences in the tests as shown in samples 6 , and 7 in Table 5 is made in favor of the developed model since it provides a greater number of reliable expert assessments.

\section{REFERENCES}

[1] M. Meira, I. Carlucho, R. Alvarez, L. Catalano, and G. Acosta, "DGA: A novel strategy for key gases identification in power transformers," in 2020 IEEE Electrical Insulation Conference, EIC 2020, Jun. 2020, pp. 290-293, doi: 10.1109/EIC47619.2020.9158662.

[2] S. Leivo and E. Briosso, "A case study, Online DGA during varying transformer conditions," in 2020 IEEE Electrical Insulation Conference, EIC 2020, Jun. 2020, pp. 348-351, doi: 10.1109/EIC47619.2020.9158665.

[3] S. J. T. Shahrabad, V. Ghods, and M. T. Askari, "Power transformer fault diagnosis using DGA and artificial intelligence," Recent Advances in Computer Science and Communications, vol. 13, no. 4, pp. 579-587, Oct. 2019, doi: $10.2174 / 2213275912666190212124133$.

[4] D. Saravanan, A. Hasan, A. Singh, H. Mansoor, and R. N. Shaw, "Fault prediction of transformer using machine learning and DGA," in 2020 IEEE International Conference on Computing, Power and Communication Technologies, GUCON 2020, Oct. 2020, pp. 1-5, doi: 10.1109/GUCON48875.2020.9231086.

[5] V. M. Levin and A. A. Yahya, "Support for decision-making to ensure reliable operation of transformers as part of a responsible power facility," Oct. 2020, doi: 10.1109/FarEastCon50210.2020.9271626.

[6] I. G. David, M. Rajaram, and A. Gnanasaravanan, "Power transformer faults identification using fuzzy based Dissolved Gas Analysis method," Journal of Electrical Engineering, vol. 13, no. 1, pp. 154-158, 2013.

[7] S. Tenbohlen, S. Coenen, M. Djamali, A. Müller, M. H. Samimi, and M. Siegel, "Diagnostic measurements for power transformers," Energies, vol. 9, no. 5, p. 347, May 2016, doi: 10.3390/en9050347.

[8] M. H. A. Hamid, M. T. Ishak, M. M. Ariffin, N. I. A. Katim, N. A. M. Amin, and N. Azis, "Dissolved gas analysis (DGA) of vegetable oils under electrical stress," in International Conference on High Voltage Engineering and Power Systems, ICHVEPS 2017 - Proceeding, Oct. 2017, vol. 2017-Jan., pp. 29-34, doi: 10.1109/ICHVEPS.2017.8225862.

[9] J. Golarz, "Understanding dissolved gas analysis (DGA) techniques and interpretations," in Proceedings of the IEEE Power Engineering Society Transmission and Distribution Conference, May 2016, vol. 2016, doi: 10.1109/TDC.2016.7519852.

[10] I. B. M. Taha, S. S. M. Ghoneim, and A. S. A. Duaywah, "Refining DGA methods of IEC Code and Rogers four ratios for transformer fault diagnosis," in IEEE Power and Energy Society General Meeting, Jul. 2016, vol. 2016-Nov., doi: 10.1109/PESGM.2016.7741157.

[11] S. S. M. Ghoneim and I. B. M. Taha, "A new approach of DGA interpretation technique for transformer fault diagnosis," International Journal of Electrical Power and Energy Systems, vol. 81, pp. 265-274, Oct. 2016, doi: 10.1016/j.ijepes.2016.02.018.

[12] M. Meira, C. Ruschetti, R. Álvarez, L. Catalano, and C. Verucchi, "Dissolved gas analysis differences between natural esters and mineral oils used in power transformers: A review," IET Generation, Transmission and Distribution, vol. 13, no. 24, pp. 5441-5448, Nov. 2019, doi: 10.1049/iet-gtd.2018.6318.

[13] R. A. Prasojo, H. Gumilang, N. U. Maulidevi, and B. A. Soedjarno, “A fuzzy logic model for power transformer faults' severity determination based on gas level, gas rate, and dissolved gas analysis interpretation," Energies, vol. 13, no. 4, pp. 1-20, 2020.

[14] O. M. Elmabrouk, R. Y. Taha, N. M. Ebrahim, and S. A. Mohammed, "An Implementation of fuzzy logic technique for prediction of the power transformer faults," International Journal of Mechanical and Industrial Engineering, vol. 13, no. 6, pp. 407-412, 2019.

[15] C. Nicola, M. Nicola, M. C. Nitu, and A.-M. Aciu, "Fuzzy logic system based on dissolved gas analysis and furan analysis for power transformer fault diagnosis," UPB Scientific Bulletin, Series C: Electrical Engineering, vol. 81, pp. 183-196, 2019.

[16] Z. Husain, "Fuzzy logic expert system for incipient fault diagnosis of power transformers," International Journal on Electrical Engineering and Informatics, vol. 10, no. 2, pp. 300-317, Jun. 2018, doi: 10.15676/ijeei.2018.10.2.8. 
[17] C. H. Liu, T. Bin Lin, L. Yao, and S. Y. Wang, "Integrated power transformer diagnosis using hybrid fuzzy dissolved gas analysis," IEEJ Trans. on Electrical and Electronic Engineering, vol. 10, no. 6, pp. 689-698, Oct. 2015, doi: 10.1002/tee.22148.

[18] N. Pattanadech and W. Wattakapaiboon, "Application of duval pentagon compared with other DGA interpretation techniques: Case studies for actual transformer inspections including experience from power plants in Thailand," Jul. 2019, doi: 10.1109/ICEAST.2019.8802523.

[19] H. C. Sun, Y. C. Huang, and C. M. Huang, "Fault diagnosis of power transformers using computational intelligence: A review," Energy Procedia, vol. 14, pp. 1226-1231, 2012, doi: 10.1016/j.egypro.2011.12.1080.

[20] S. B. Wanjare and P. S. Swami, "DGA interpretation for increasing the percent of accuracy by different methods: a review," in 7th IEEE International Conference on Computation of Power, Energy, Information and Communication, ICCPEIC 2018, Mar. 2018, pp. 458-461, doi: 10.1109/ICCPEIC.2018.8525179.

[21] M. Grisaru, "Basic principles of DGA - Part II Learning, using, and creating your own view on DGA," Transformers Magazine, Jan. 2021.

[22] IEEE Std C57.104, "IEEE guide for the interpretation of gases generated in oil-immersed transformers,2019-06-13," Ieee, vol. 2019. IEEE, pp. 0-97, 2019, doi: 10.1109/ieeestd.2019.8890040.

[23] S. Apte, R. Somalwar, and A. Wajirabadkar, "Incipient fault diagnosis of transformer by DGA using fuzzy logic," Dec. 2018, doi: 10.1109/PEDES.2018.8707928.

[24] R. A. Prasojo, H. Gumilang, Suwarno, N. U. Maulidevi, and B. A. Soedjarno, "A fuzzy logic model for power transformer faults' severity determination based on gas level, gas rate, and dissolved gas analysis interpretation," Energies, vol. 13, no. 4, Feb. 2020, Art. no. 1009, doi: 10.3390/en13041009.

[25] R. Palke and P. Korde, "Dissolved gas analysis (DGA) to diagnose the internal faults of power transformer by using fuzzy logic method," in Proceedings of the 2020 IEEE International Conference on Communication and Signal Processing, ICCSP 2020, Jul. 2020, pp. 1050-1053, doi: 10.1109/ICCSP48568.2020.9182279.

[26] O. M. Elmabrouk, F. A. Masoud, and N. S. Abdelwanis, "Diagnosis of power transformer faults using fuzzy logic techniques based on IEC ratio method," Aug. 2020, doi: 10.1145/3410352.3410770.

[27] S. Genc and S. Karagol, "Fuzzy logic application in DGA methods to classify fault type in power transformer," Jun. 2020, doi: 10.1109/HORA49412.2020.9152896.

[28] F. Mohamad, K. Hosny, and T. Barakat, "Incipient fault detection of electric power transformers using fuzzy logic based on roger's and IEC method," in Proceedings - ICCES 2019: 2019 14th International Conference on Computer Engineering and Systems, Dec. 2019, pp. 303-309, doi: 10.1109/ICCES48960.2019.9068132.

[29] A. Abu-Siada and S. Hmood, "A new fuzzy logic approach to identify power transformer criticality using dissolved gas-in-oil analysis," International Journal of Electrical Power \& Energy Systems, vol. 67, pp. 401-408, May 2015, doi: 10.1016/j.ijepes.2014.12.017.

\section{BIOGRAPHIES OF AUTHORS}
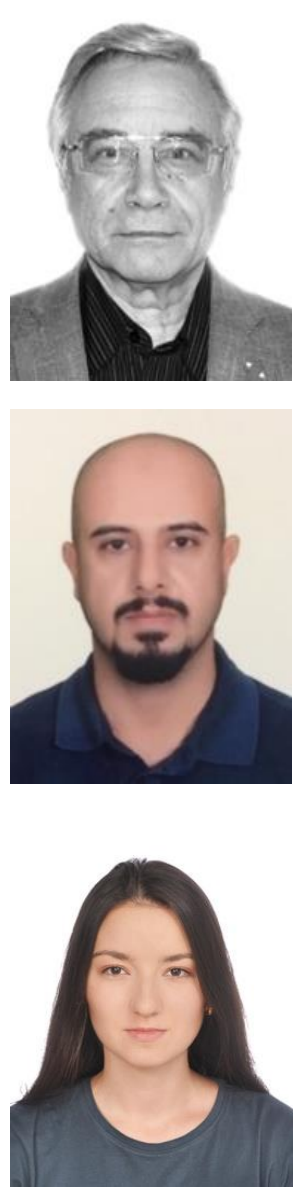

Vladimir Mikhailovich Levin (iD IS SC P was born in Omsk, Russian Federation in 1954 year. He received a degree in power engineering from the Novosibirsk Electro technical Institute in 1976. In 1983 he received a degree of candidate of technical sciences in the field of electrical power stations and electric power systems. The degree of Doctor of Technical Sciences in the same scientific specialty he received in 2017. Presently he works as the head of the Department of Automated Electric Power Systems at the Novosibirsk State Technical University, Novosibirsk. His scientific interests are in the field of diagnostics and reliability of electric power systems, developing methods and mathematical models for adaptive management of the technical state of electrical equipment of power plants and electrical network and asset management. He can be contacted at email: levin@corp.nstu.ru.

Ammar Abdulazeez Yahya (iD SII SC P was born in Baghdad, Iraq, in 1985. He received the B.Sc. degree from the University of Technology, Baghdad, Iraq, in 2007, the M.Sc. degree from Platov South-Russian State Polytechnic University, Rostov on Don, Russia in 2015. Now he is studying PhD 4 year at Novosibirsk State Technical University. He works as a teacher at University of Technology in Baghdad, Iraq. His scientific interests are in the field of diagnostics, monitoring and reliability of electric power systems. He can be contacted at email: ammarazez384@gmail.com.

Diana A. Boyarova (D) $8 \mathrm{SC}$ P was born in 1999 in Tashkent, Uzbekistan. In 2020 she received a bachelor's degree in Electrical Power and Electrical Engineering. Nowadays she is continuing her studies in the magistracy at the Department of Automated Electric Power Systems in NSTU. Research interests: management of technical maintenance and repair of electrical equipment according to technical condition, reliability of electrical power systems. She can be contacted at email: zykova_diana@mail.ru. 